Report No. BMI- 1336

UC-40 Radiation Effects on Materials (TID-4500, 14th Ed.)

Contract No. W-7405-eng-92

DESCRIPTION OF A CAPSULE FOR IRRADIATION

OF FUEL SPECIMENS AT HIGH TEMPERATURES

$$
\text { by }
$$

Sam J. Basham

John H. Stang

William H. Goldthwaite

Bruce W. Dunnington

\author{
April 22, 1959 \\ BATTELLE MEMORIAL INSTITUTE \\ 505 King Avenue \\ Columbus 1, Ohio
}




\section{DISCLAIMER}

This report was prepared as an account of work sponsored by an agency of the United States Government. Neither the United States Government nor any agency Thereof, nor any of their employees, makes any warranty, express or implied, or assumes any legal liability or responsibility for the accuracy, completeness, or usefulness of any information, apparatus, product, or process disclosed, or represents that its use would not infringe privately owned rights. Reference herein to any specific commercial product, process, or service by trade name, trademark, manufacturer, or otherwise does not necessarily constitute or imply its endorsement, recommendation, or favoring by the United States Government or any agency thereof. The views and opinions of authors expressed herein do not necessarily state or reflect those of the United States Government or any agency thereof. 


\section{DISCLAIMER}

Portions of this document may be illegible in electronic image products. Images are produced from the best available original document. 
TABLE OF CONTENTS

$\underline{\text { Page }}$

ABSTRACT

INTRODUCTION

GENERAL DESIGN DESCRIPTION

DISCUSSION

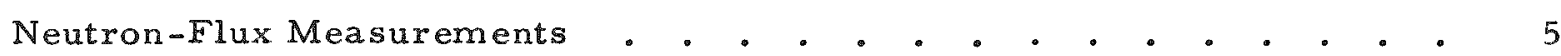

Heat Transfer and Temperature Distribution . . . . . . . . . . 5

Radiation Losses . . . . . . . . . . . . . . . . . . . 10

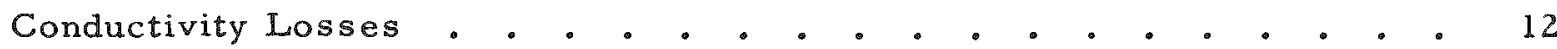

Thermal-Mock-Up Experiments . . . . . . . . . . . . . . 15

Irradiation-Capsule Data . . . . . . . . . . . . . . . . 15

Miscellaneous Details . . . . . . . . . . . . . . . . 19

Strength Considerations . . . . . . . . . . . . . . . 19

Suspensions and Supports . . . . . . . . . . . . . 21

Thermocouples . . . . . . . . . . . . . . . 21

Dosimeter Wires . . . . . . . . . . . . . . . 21

Auxiliary Heaters . . . . . . . . . . . . . . . 21

Hot-Cell Gas-Sampling Apparatus . . . . . . . . . 22

Configuration of Outer Shell . . . . . . . . . . . . . 22

Aluminum Sleeve (Heat-Flow Barrier) . . . . . . . . . . 22

External Locating Fixture . . . . . . . . . . . . . . 22

Capsule-to-Pool Surface Lead Tube . . . . . . . . . . . 23

Temperature Instrumentation . . . . . . . . . . . . 23

Inspection Procedures During Assembly . . . . . . . . . 23

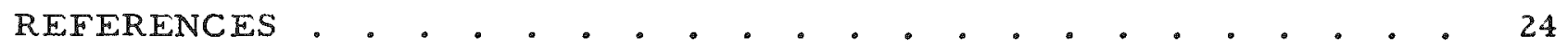




\title{
DESCRIPTION OF A CAPSULE FOR IRRADIATION OF FUEL SPECIMENS AT HIGH TEMPERA TURES
}

\author{
Sam J. Basham, John H. Stang, William H. Goldthwaite, \\ and Bruce $W$. Dunnington
}

\begin{abstract}
A controlledbremp erature irradiation copsule was operated contcaining small fueled specimens at 1600 to $1650 \mathrm{~F}$. The design involved calculating the specimen heat-generation rate and designing an insulating gas gap around the specimens to achieve the desired semperaiure. Electric heaters were inserted to help control temperature. The thicliness and composition of the gas gap were modified prior to operation on the basis of information on probable neutron flux obtained from a nuclear mock-up, and on the basis of information on the thermal resistance of various gas annuli obtained from a thermal mock-up. The desired irradiation cemperature of $1625 F$ was achieved with a variation of $\pm 25 F$.
\end{abstract}

\section{INTRODUCTION}

One of the major problems in capsule irradiation tests is that uncertainties in the neutron flux and the rate of heat loss may combine to give large uncertainties in the temperature and burnup of the specimen. The magnitude of the problem increases as the desired temperature of irradiation increases. In the present case, a capsule was designed for use in the core of the Battelle Research Reactor to permit irradiation of small fuel specimens in NaK above $1600 \mathrm{~F}$ in a flux on the order of $10^{13} \mathrm{nv}$. The design can be applied to a wide variety of flux levels, irradiation temperatures, and specimen configurations and loadings. Considerable design detail is provided in this report to encourage such application. An outside diameter of $2 \mathrm{in}$. was optimum for the current application which eliminates this design in its present form from use in the standard A-pieces in the MTR, where the maximum allowable diameter is $1-1 / 8$ in. However, it is believed that the design details are of general application.

\section{GENERAL DESIGN DESCRIPTION}

The capsule design described here is suitable for controlled-temperature irradiation up to somewhat above $1600 \mathrm{~F}$ of specimens generating from zero to $5000 \mathrm{w}$ of fission heat. Two 1500-w electric heaters are built into the capsule. At zero specimenheating rate (i.e., no fission heating), the specimen can be maintained at any temperature up to the maximum by selecting the maximum available heat barrier values, and heating with the auxiliary heaters. At $5000 \mathrm{w}$, the minimum available heat barrier values would be selected, and the auxiliary heaters would be used to a minor extent for control purposes. At specimen-heating rates above $5000 \mathrm{w}$ it would be more suitable to use metal fins as the adjustable heat barrier. 
The capsule consists of inner and outer stainless steel shells. The inner shell or crucible contains the specimens in a NaK bath. The crucible is wrapped with an electric heater and is separated from the outer shell by an insulating gas gap and an aluminum liner. Figure 1 is a schematic view of the completed capsule together with its end fittings, and shows the internal construction and the positioning of specimens. Figure 2 is an engineering drawing showing the details of capsule construction.

A critical general consideration in capsule irradiations is the reliability of com ponents. The items that most frequently fail are seals, heaters, and thermocouples. Furnace brazing is used in this case to give highly reliable seals of the thermocouple and heater leads into the capsule shells. Malfunctioning of heaters and thermocouples cannot be eliminated, but the frequency of occurrence can be kept low by painstaking inspection and testing of components. Protection against malfunctioning can be achieved by insertion of multiple components so that the capsule will function despite failure of some components.

The desired temperature must be maintained despite changes or uncertainties in the rate of fissioning and the rate of heat dissipation. An optimum auxiliary heat source must therefore cover a large enough range of heat generation to insure a proper heat balance at all times. The heat-dissipation characteristics must be tailored to the specific specimen, flux, and desired temperatures. In this design the heat dissipation can be changed by changes in the composition of the insulating gas, the thickness of the gas layer, and the emissivity of the internal surfaces.

Errors in assigning the magnitude of the uncertainties may result in a capsule that will not perform the intended function. (1) Such errors are commonplace and are unavoidable in many instances because of erratic changes in reactor environment in local regions. Another source of such errors is that the cost of obtaining reliable data may be prohibitive. The existence of such potential errors places a premium on a capsule design, such as the present one, that will operate over a wide variety of heatgeneration rates.

With this general description of the capsule as background information, each im portant item of the design is treated in detail in the discussion below. The design examples in some cases do not represent initial calculations, but rather represent the conditions that were subsequently shown by thermal-mock-up experiments to be the actual cases. This approach was chosen because it describes the existing design and the basic methods used to arrive at this design.

(1) References at end. 


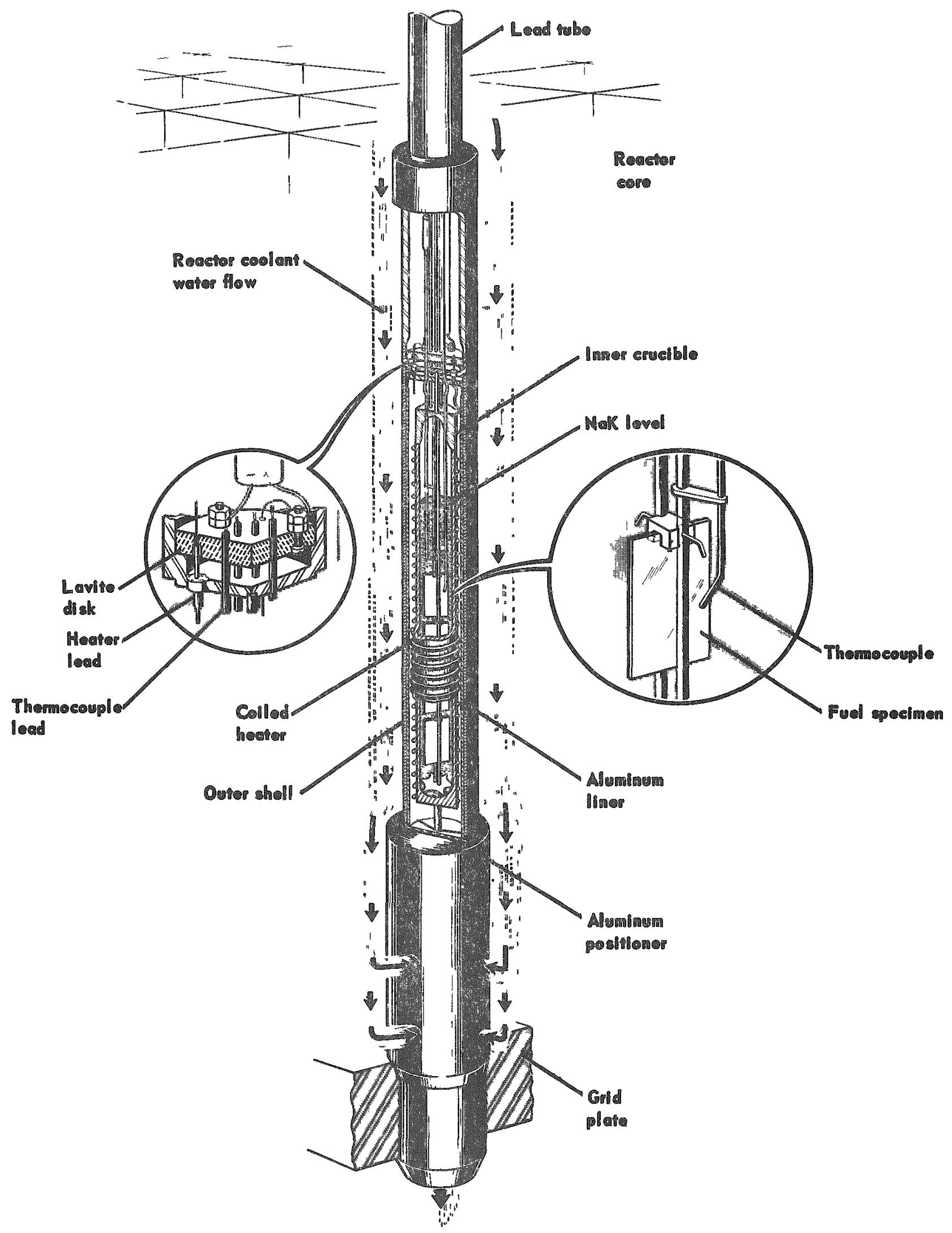

FIGURE 1. SCHEMATIC VIEW OF COMPLETED CAPSULE POSITIONED IN REACTOR 


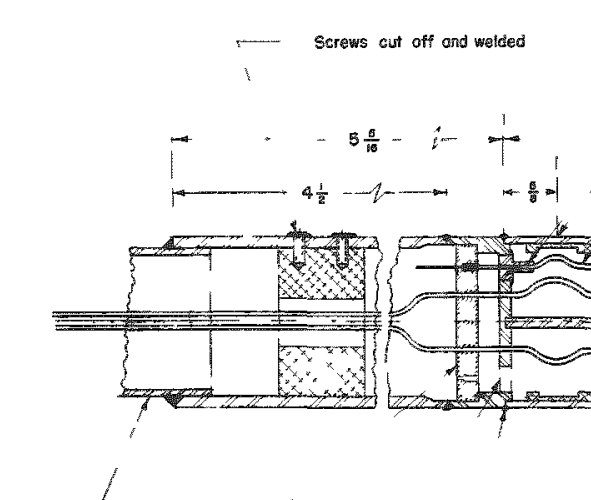

Laed dsetat
Lovite disk Mooter sleave

LFinal weld

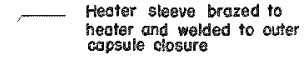

Nak level of temperature

- Outer shell

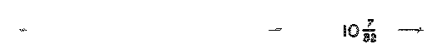

Cut here

$10 \frac{7}{32} \rightarrow$

Cut here $\begin{gathered}G a s \text { sample } \\ \text { perengng boss }\end{gathered}$

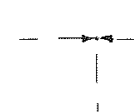

$5 \frac{h^{4}}{18}-$

- Specirnens Cut here -..m

13

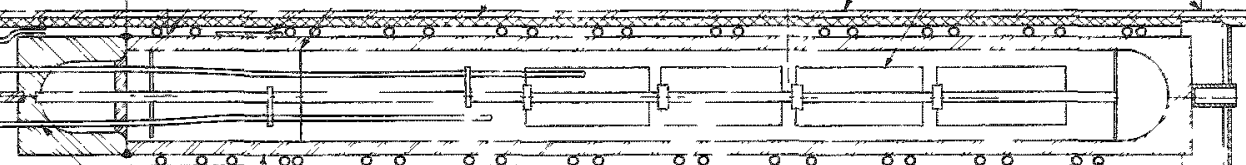

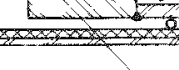

-inner crucibls

Themocouples brozed to closures (1, in oD stanless steel
sheath- type Chromel Alumel - eight present)

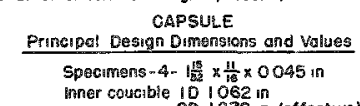

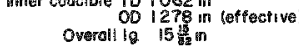

curer streal $10: 830$, in

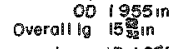

$\begin{array}{rl}\text { Aluminum sleeve } & 101605 \text { in } \\ 00 & 1800 \text { in } \\ \text { Overall ig } 158 \text { in }\end{array}$

B 31200

FIGURE 2. IRRADIATION CAPSULE ASSEMBLY 


\section{DISCUSSION}

Neutron-Flux Measurements

Efficient design of a temperature-controlled capsule requires a knowledge of the effective neutron flux. Unfortunately, changes in operating conditions of the reactor make accurate predictions of flux impossible, even though the total reactor power is constant. Consequently, the capsule designer must use the best available estimate of the neutron flux as the basis for establishing approximate design conditions.

The reactor test space chosen for this experiment was Position 33 in the core of the Battelle Research Reactor. A map of the BRR core is shown in Figure 3 with the appropriate features indicated. At the time the flux was measured, fuel elements (MTR-type) were operating in each of the 31 positions indicated except for those occupied by the four safety-rod assemblies and the regulating rod. The safety and regulating rods consist of fuel elements modified to accommodate the absorber material by removal of four of the ten fuel plates. The absorber material in the safety assemblies is boron carbide ( $\left.\mathrm{B}_{4} \mathrm{C}\right)$. These assemblies are also used to shim the reactor during operation. The absorber material in the regulating rod is stainless steel.

An effective thermal-neutron flux in the specimens of about $1 \times 10^{13} \mathrm{n} /\left(\mathrm{cm}^{2}\right)(\mathrm{sec})$ was measured by use of the nuclear-mock-up capsule shown in Figure 4 . The estimated error in measurement was \pm 15 per cent. Four 1 by 0.5 by 0.021 tantalum specimens were clustered and used to simulate the fuel specimens and two manganese-iron dosimeter wires were included within the assembly, one running through the center of the capsule and the tantalum specimens, and the other running about $1 / 2$ in. from the center line and along the edges of the tantalum. The thickness and amount of tantalum were chosen to give an absorption equivalent to that of the fuel specimens. Two irradiations were made, one with the capsule and dosimeter wires, and the other with a wire in the center of the empty test cell to obtain relative fluxes directly. The flux distributions in the nuclear mock-up and in the empty test cell are shown in Figure 5. The flux in the empty cell was corrected for the epithermal contributions by measurements with cadmium-covered dosimeter wires.

Heat Transfer and Temperature Distribution

The initial design was arrived at by assuming simplified geometrical configurations and boundary conditions, and applying the appropriate idealized expressions for heat flow and temperature distribution. The design was then modified by using data from thermal calibration tests relating the rate of internal heat generation to the temperature drop through the capsule walls. In simpler cases it is frequently adequate to use analog solutions that partially simulate the actual capsule conditions.

Figure 6 shows a schematic drawing of the idealized cross section of the capsule used for calculations of heat transfer and temperature distribution. A typical temperature distribution is shown for the case where the specimen is operating at about $1600 \mathrm{~F}$. 


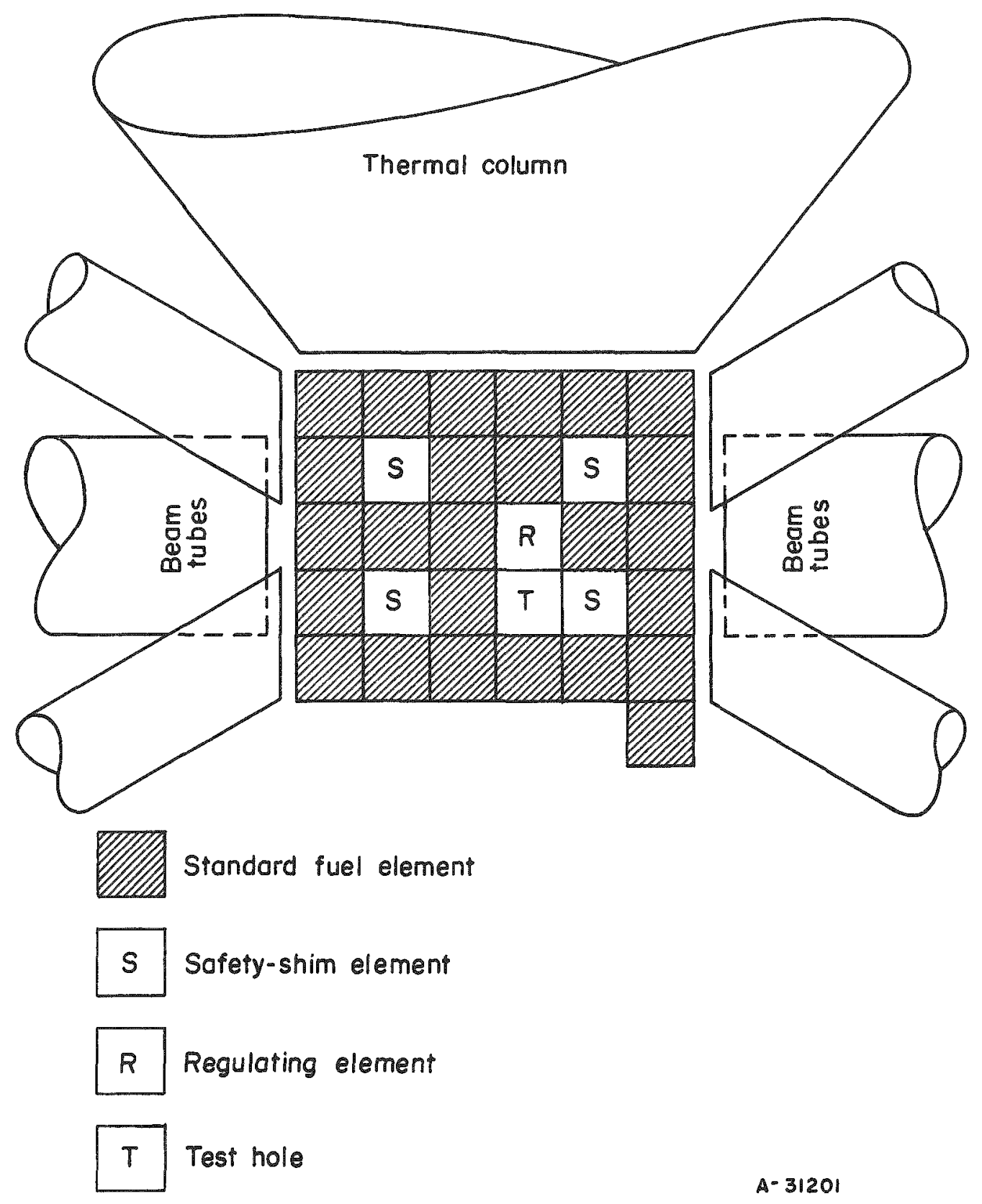

FIGURE 3. HORIZONTAL SECTION OF REACTOR 


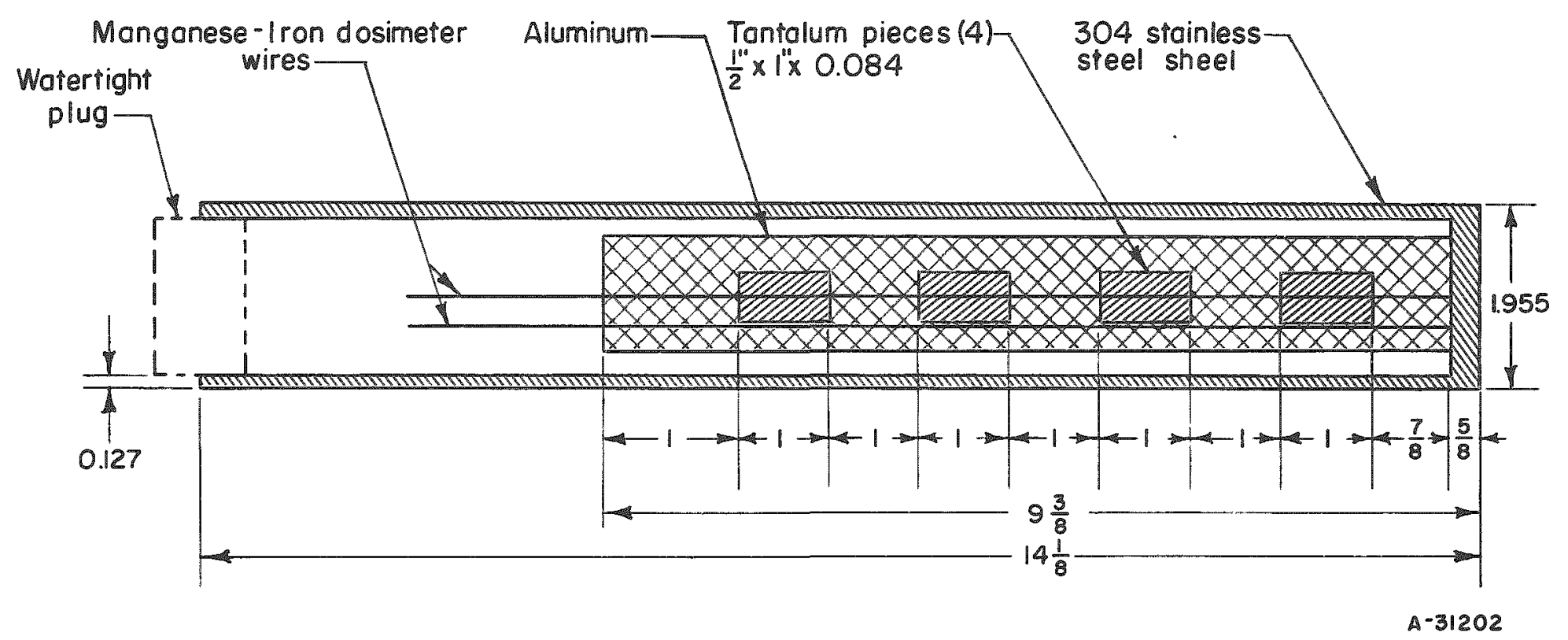

FIGURE 4. NUCLEAR MOCKUP CAPSULE 
Thermal Neuiron Flux, neutrons $/ \mathrm{cm}^{2} / \mathrm{sec} \times 10^{13}$

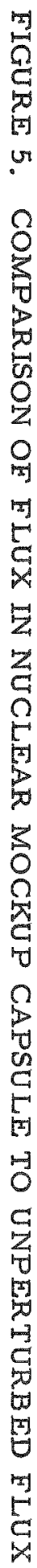

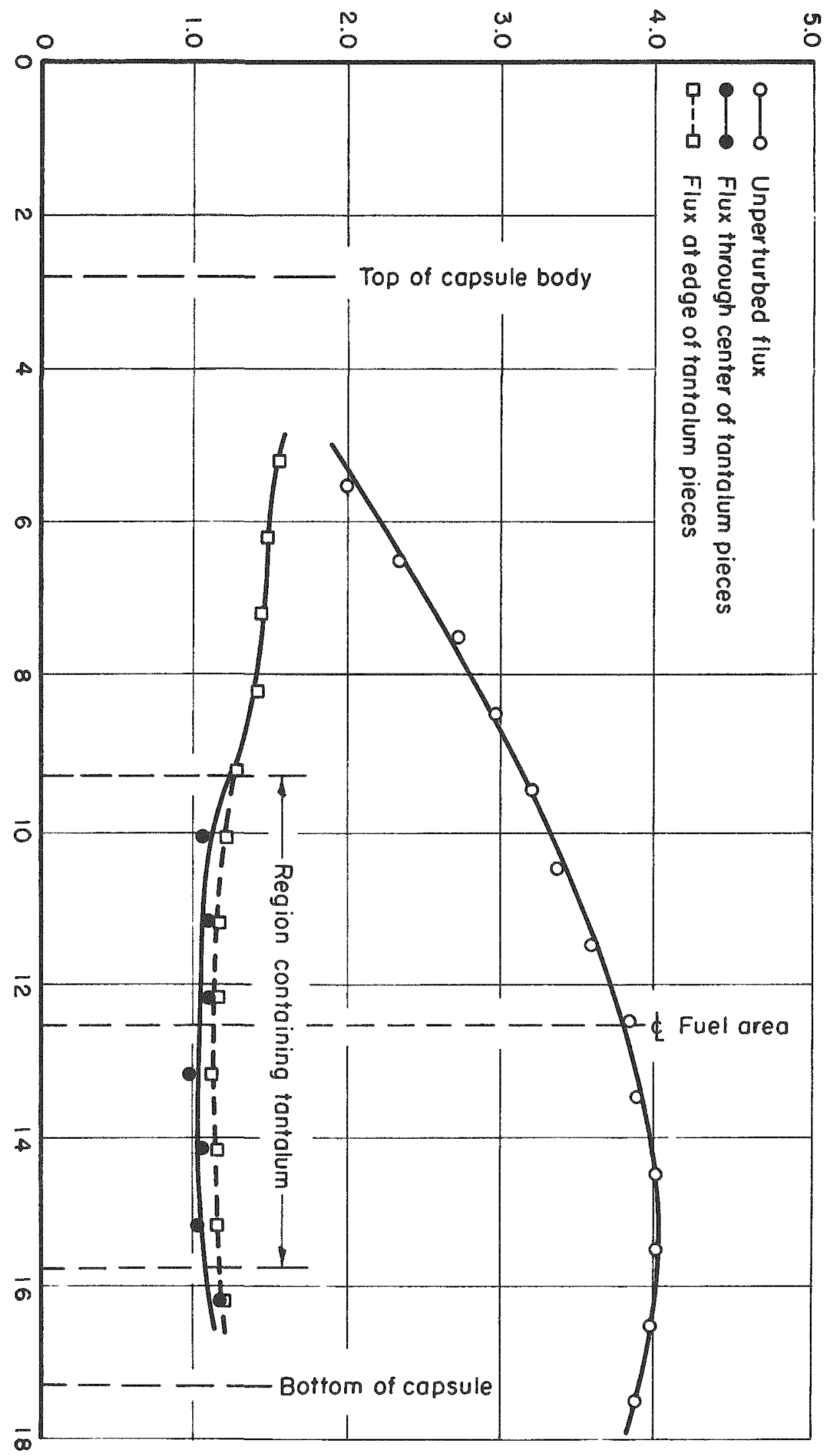




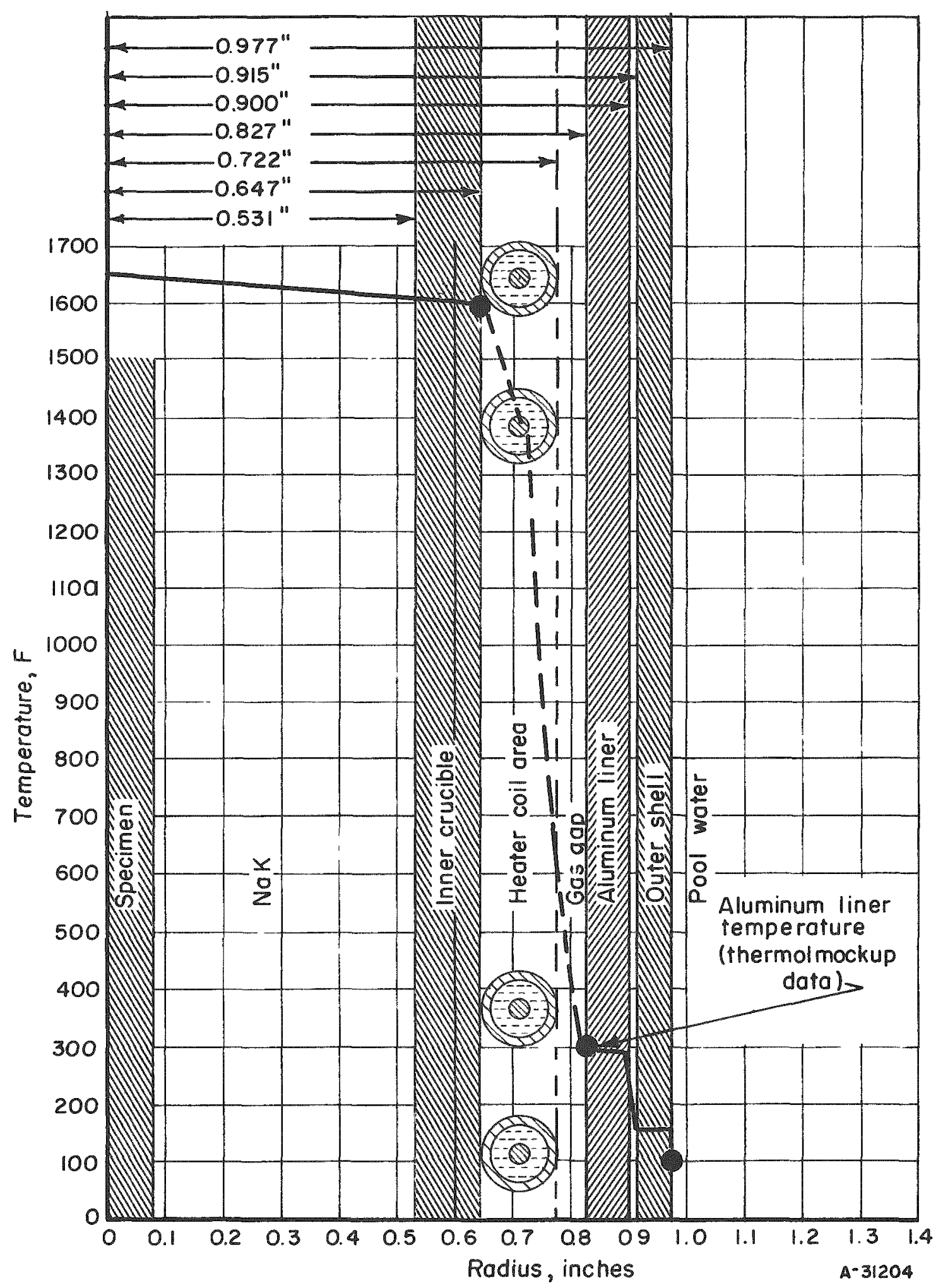

FIGURE 6. APPROXIMATE RADIAL TEMPERATURE DISTRIBUTION 
This drawing emphasizes that the major heat barrier in this design is the gas gap. It is clear that the temperature distribution and heat flow in a gap of this configuration will be complex. The temperature drops through the other parts of the capsule are relatively much smaller. Design calculations were made to relate the temperature drops through the various walls to the heat throughput, but these will not be repeated here because initial calculations showed they were small compared to the uncertainty in conduction across the gas gap.

The bulk of the design of the capsule is fixed by considerations other than heat transfer. The problem then is to examine the influence of the variable heat barriers that can be built into the design. The heat transfer across the gas gap can be varied by changing the emissivities of the surfaces, the width of the gap, and the thermal conductivity of the gas. Each of these possible variables is discussed below.

\section{Radiation Losses}

Examination of the complex configuration of the radiating surfaces in the gas gap indicates that any reasonable mathematical treatment can be only approximate. Consider that the problem is one of radiation between two large parallel plates. The rate of transfer of heat by radiation is then $(2)$

$$
\mathrm{q}_{\mathrm{r}}=\frac{\sigma}{\frac{1}{\mathrm{E}_{1}}+\frac{1}{\mathrm{E}_{2}}-1}\left(\mathrm{~T}_{1}^{4}-\mathrm{T}_{2}^{4}\right) \mathrm{Btu} /(\mathrm{hr})\left(\mathrm{ft}^{2}\right)
$$

where $\sigma$ is the Stefan-Boltzmann constant, $0.171 \times 10^{-8} \mathrm{Btu} /(\mathrm{hr})\left(\mathrm{ft} \mathrm{t}^{2}\right)\left(\mathrm{F}^{4}\right)$

$E_{1}$ and $E_{2}$ are the emissivities of the two radiating surfaces

$T_{1}$ and $T_{2}$ are the temperatures of the two radiating surfaces, $R$.

Assume that radiation takes place only radially along a 10-in. length of capsule, and, because of the complicated nature of the radiative surface (heater surface plus inner shell surface), that the area of the inside surface of the corresponding length of the outer shell represents the radiating area. This area is $\pi \mathrm{DL}$ or $0.35 \mathrm{ft}^{2}$. Experience with the thermal mock-up eventually showed that, for the conditions of interest, the temperature of inner surface of the aluminum liner was about $300 \mathrm{~F}$; therefore, this value will be used in this design demonstration.

Figure 7 shows rates of heat loss predicted by this model for various emissivities and various capsule temperatures. In the present application the curves for $1600 \mathrm{~F}$ are the only ones of interest. It is assumed that the surface of the heater and the inner crucible will be oxidized, with an emissivity approaching unity. If the design were made on the basis of highly reflective surfaces there would be the hazard that minor changes in the gas content would tarnish the surface and cause greater heat losses than anticipated. Similar reasoning applies to the outer wall even though it is relatively cold and, 


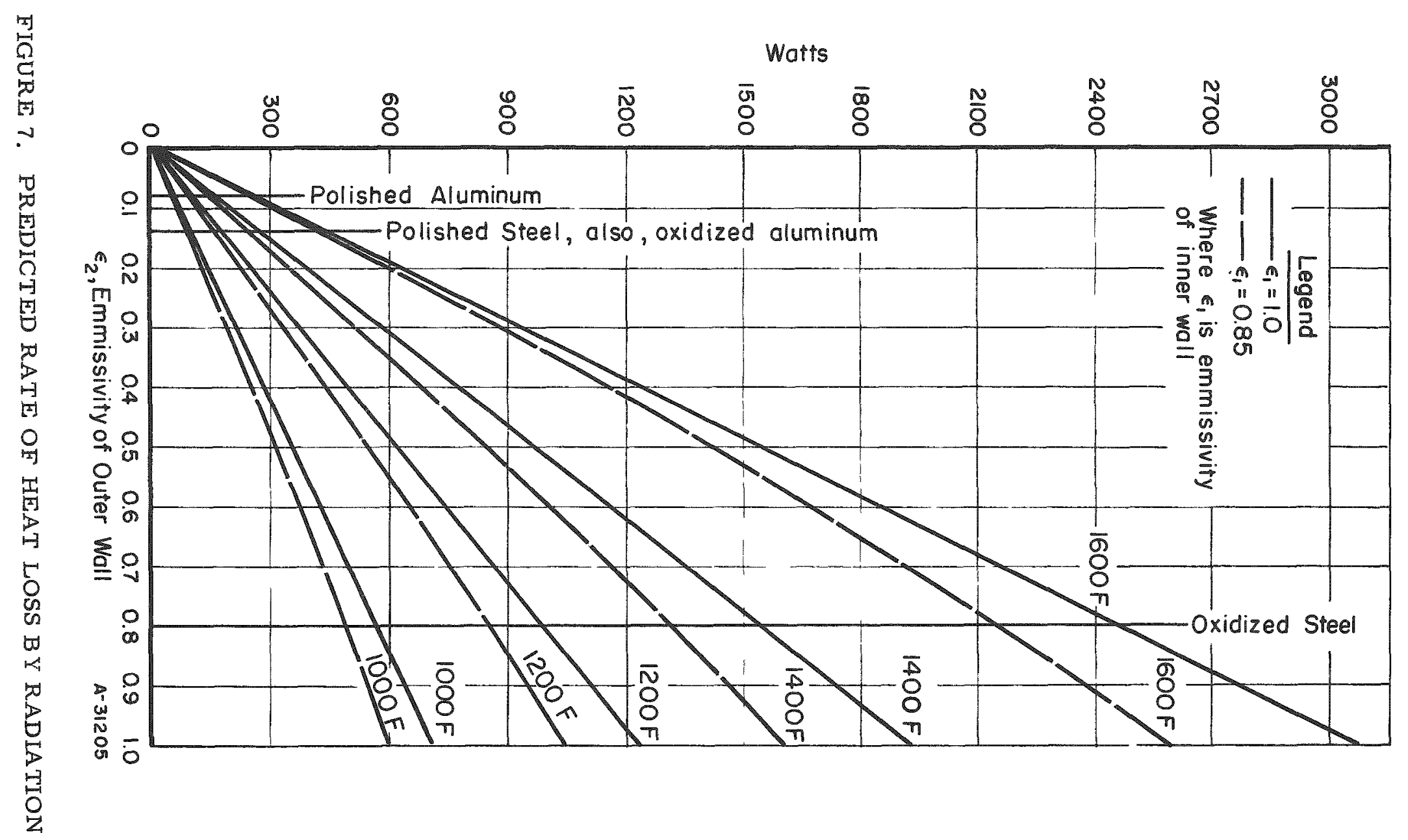


hence, less likely to become tarnished. Figure 7 shows that at $1600 \mathrm{~F}$ the rate of heat loss would change from about $450 \mathrm{w}$ to about $2400 \mathrm{w}$ if the outer-wall emissivity changed from the value of oxidized aluminum to that of oxidized steel.

Figure 7 indicates a radiative heat loss of about $450 \mathrm{w}$ in the present case, assuming the outer wall to be oxidized aluminum.

\section{Conductivity Losses}

The rate of conductive heat transfer through the gas gap can be varied over a wide range by using a helium-argon gas mixture and controlling the ratio of helium to argon. Figure 8 is a plot of the thermal conductivity of various gas mixtures at different temperatures. These plots were obtained by curves matching the conductivity-versus temperature values of the pure gases $(3)$ to the volume percentage-versus-conductivity values at $32 \mathrm{~F}^{(4)}$. A temperature of $1150 \mathrm{~F}$ was presumed to be approximately the mean temperature of the gas in the present application. At $1150 \mathrm{~F}$, the thermal-conductivity values of the gas mixtures vary from $0.023 \mathrm{Btu} /(\mathrm{hr})(\mathrm{ft})(\mathrm{F})$ for pure argon to 0.188 Btu/(hr) (ft $)(F)$ for pure helium.

An estimate of the rate of heat transfer by conduction can be obtained by using a simplified model with potential inaccuracies similar to those in the case of radiation losses. Assume a stagnant gas layer between concentric cylinders. The rate of heat transfer is then(5)

$$
\mathrm{q}_{c}=\frac{2 \pi k\left(\mathrm{~T}_{1}-\mathrm{T}_{2}\right)}{\ln \left(\mathrm{r}_{2} / \mathrm{r}_{1}\right)}
$$

Examination of Figure 6 indicates the difficulty of choosing an inner radius for the conducting gas ring. Recognizing the difficulties, a value of $0.709 \mathrm{in}$. will be used, representing the center line of the heater coils. A value of $300 \mathrm{~F}$ will be used for $T_{2}$ as in the previous case. Figure 9 shows a plot of the predicted conductive heat losses for a 10-in. effective length and an inner-capsule temperature of $1600 \mathrm{~F}$. The heat loss is shown as a function of gap thickness for various gas mixtures. The minimum practical gas gap for smooth concentric cylinders is considered to be about $0.040 \mathrm{in}$. Use of this chart requires an interpretation of the equivalent gap thickness in the actual capsule. Recalling that the calculations were made on the assumption that the equivalent inner wall was at the center line of the 1/8-in. -diameter heater, it is seen that a gas gap on the figure of 0.062 -in. is equivalent to the heater touching the enclosing wall. The actual gap used in the capsule would be $0.118 \mathrm{in}$. on this graph, indicating a clearance of about $0.055 \mathrm{in}$. between the heater and the enclosing wall. These calculations indicate a conductive heat loss of about $1400 \mathrm{w}$ for an argon-70 volume per cent helium mixture and the dimensional conditions of the irradiation capsule. 


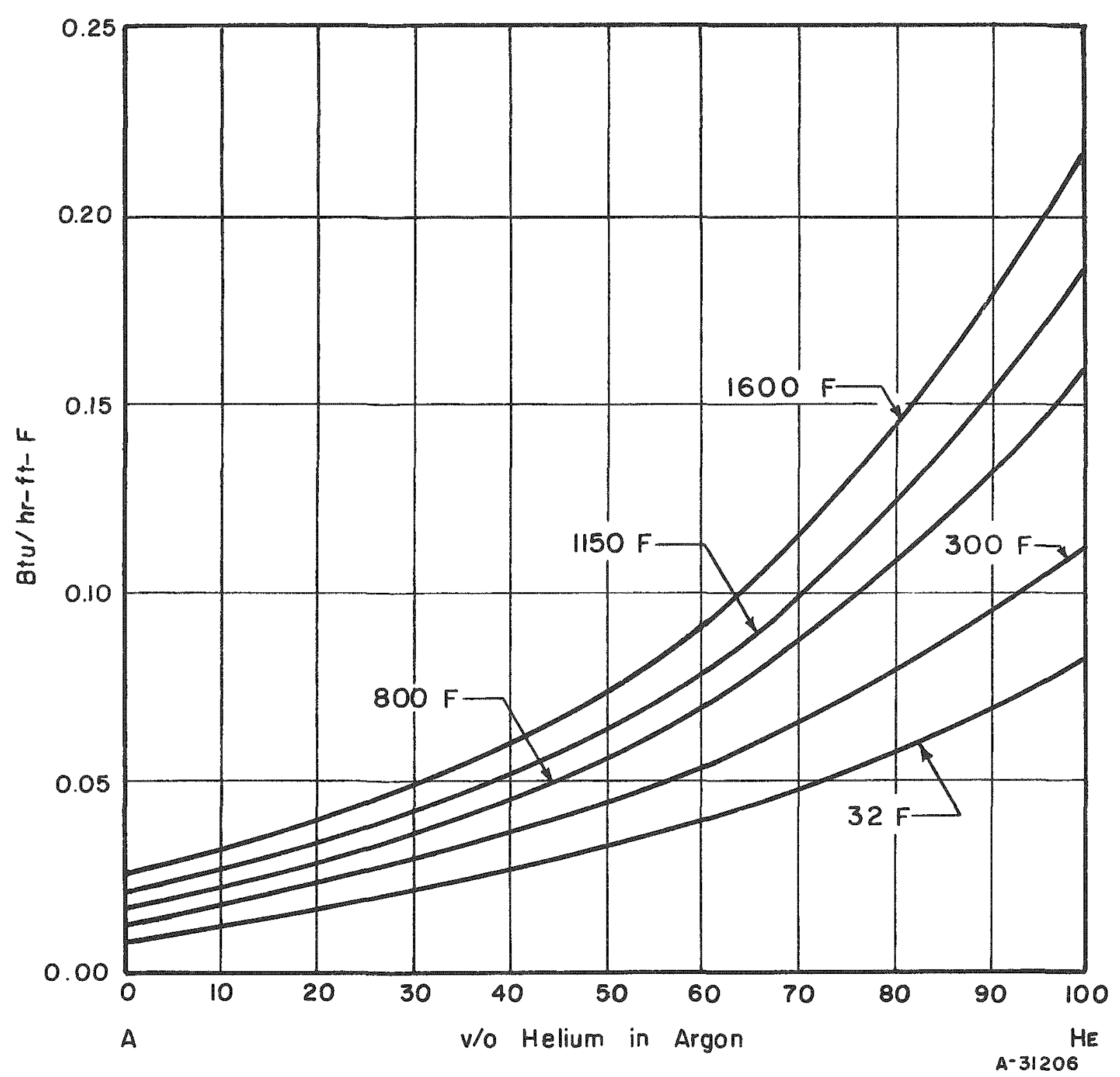

EIGURE 8. THERMAL CONDUCTIVITY OF ARGON-HELIUM GAS MIXTURES 


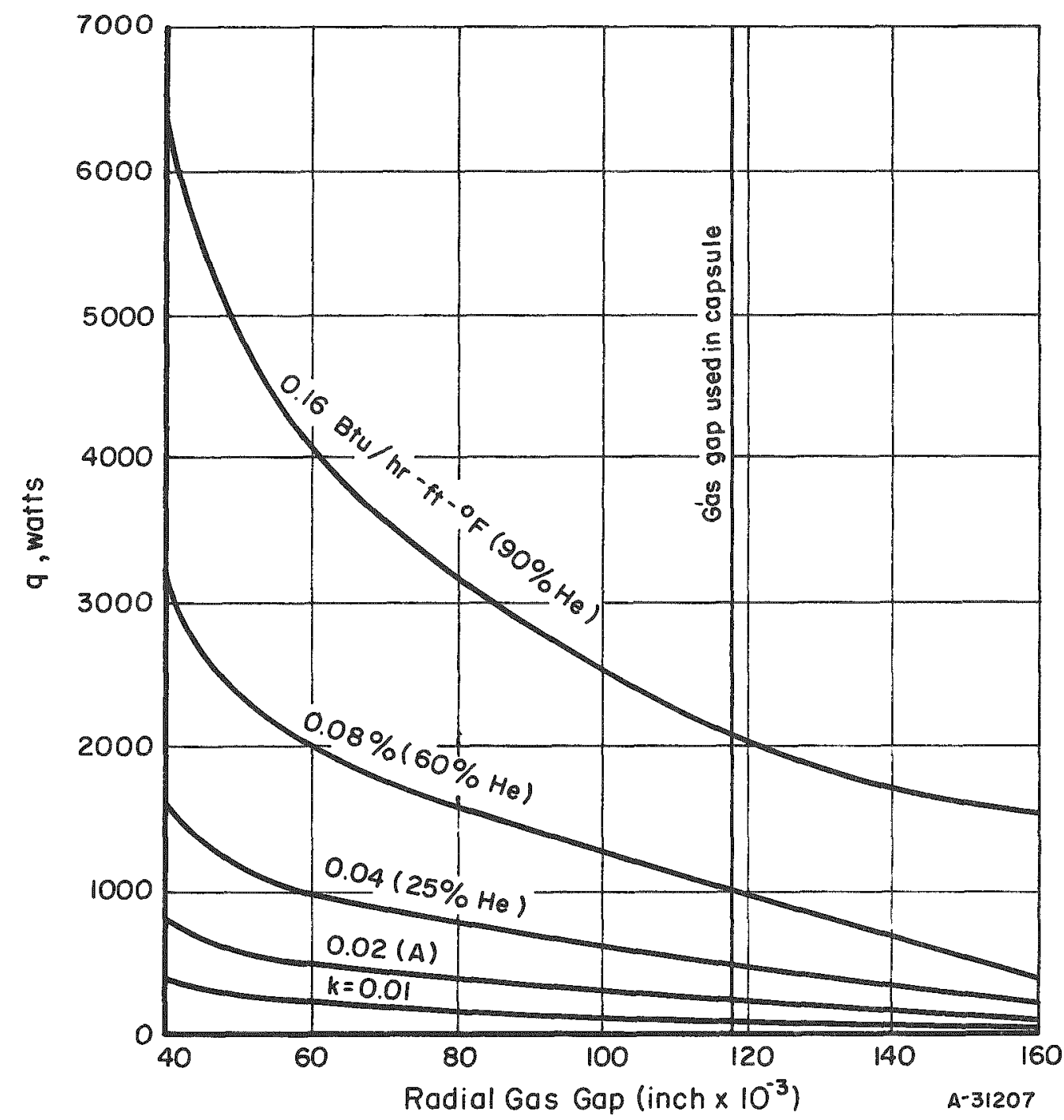

FIGURE 9. ESTIMATED HEAT LOSS DUE TO CONDUCTION WITH INNER CAPSULE WALL TEMPERATURE OF $1600^{\circ} \mathrm{F}$ 
Thermal-Mock-Up Experiments

Calculations of the type discussed above indicated a total heat-dissipation rate across the gas gap of about $1850 \mathrm{w}$, obtained by adding the $450 \mathrm{w}$ by radiation to the $1400 \mathrm{w}$ by conduction. Recognizing the uncertainties in the calculational methods employed, a direct evaluation was made of the heat-transfer characteristics of the basic capsule design. The thermal-mock-up experiments were run with a capsule equipped with 1/16-in.-diameter heaters and other dimensions and materials as indicated in the previous figures. The only control variable was the composition of the gas in the gap.

The thermal-mock-up data are shown in Figure 10. These preliminary data indicated lower rates of heat loss than the previous calculations would indicate. The gas mixture for the irradiation capsule was selected so that the capsule would function either with the low heat-dissipation rate measured in the mock-up or with the higher heat-dissipation rate derived from calculations. Argon-70 volume per cent helium was chosen because with this ratio even the lower value of heat dissipation predicted by the thermal mock-up data would handle the maximum fission heating predicted. Two 1500 -w heaters were incorporated for auxiliary heating so that if the fission heat were less and the heat dissipation were as great as predicted by the calculations, the difference could be made up by electric heat.

Part of the thermal-mock-up experiments involved a measurement of the axial distribution of temperature. Figure 11 shows the results of these measurements. It is seen that there is a relatively uniform temperature over the entire length occupied by the specimens. A power input of $2450 \mathrm{w}$ was required to maintain the actual irradiation-capsule wall at $1600 \mathrm{~F}$.

Irradiation-Capsule Data

A complete calibration curve for the irradiation capsule is shown in Figure 12. The heater power is plotted against the measured temperature of the inner-capsule wall. The calibration was repeated, up to about $1200 \mathrm{~F}$, in the reactor immediately after insertion and again after a small amount of irradiation. No change was noted in the calibration curve up to the maximum power used, which was $1300 \mathrm{w}$. When the capsule was calibrated by electric-heater power, the heat source was close to the outer wall. When the capsule was calibrated by fission heat, the heat source was in the center of the inner shell.

The maximum inner-wall temperature achieved by fission heat alone was $1190 \mathrm{~F}$, and by assuming a direct correlation between fission and heater-power temperature relations, this temperature is associated on the plot with a nuclear heating rate of $1400 \mathrm{w}$. About $1150 \mathrm{w}$ of additional electric heat was required to increase the temperature to $1600 \mathrm{~F}$.

The specimens used in this particular experiment contained an amount of uranium-235 such that an effective flux of $1013 \mathrm{nv}$ would produce $780 \mathrm{w}$ of fission heat. It was estimated that at full reactor power the gamma heat in the inner crucible would be about $200 \mathrm{w}$. The selected heating rate of $1400 \mathrm{w}$ therefore implies a fission heating 


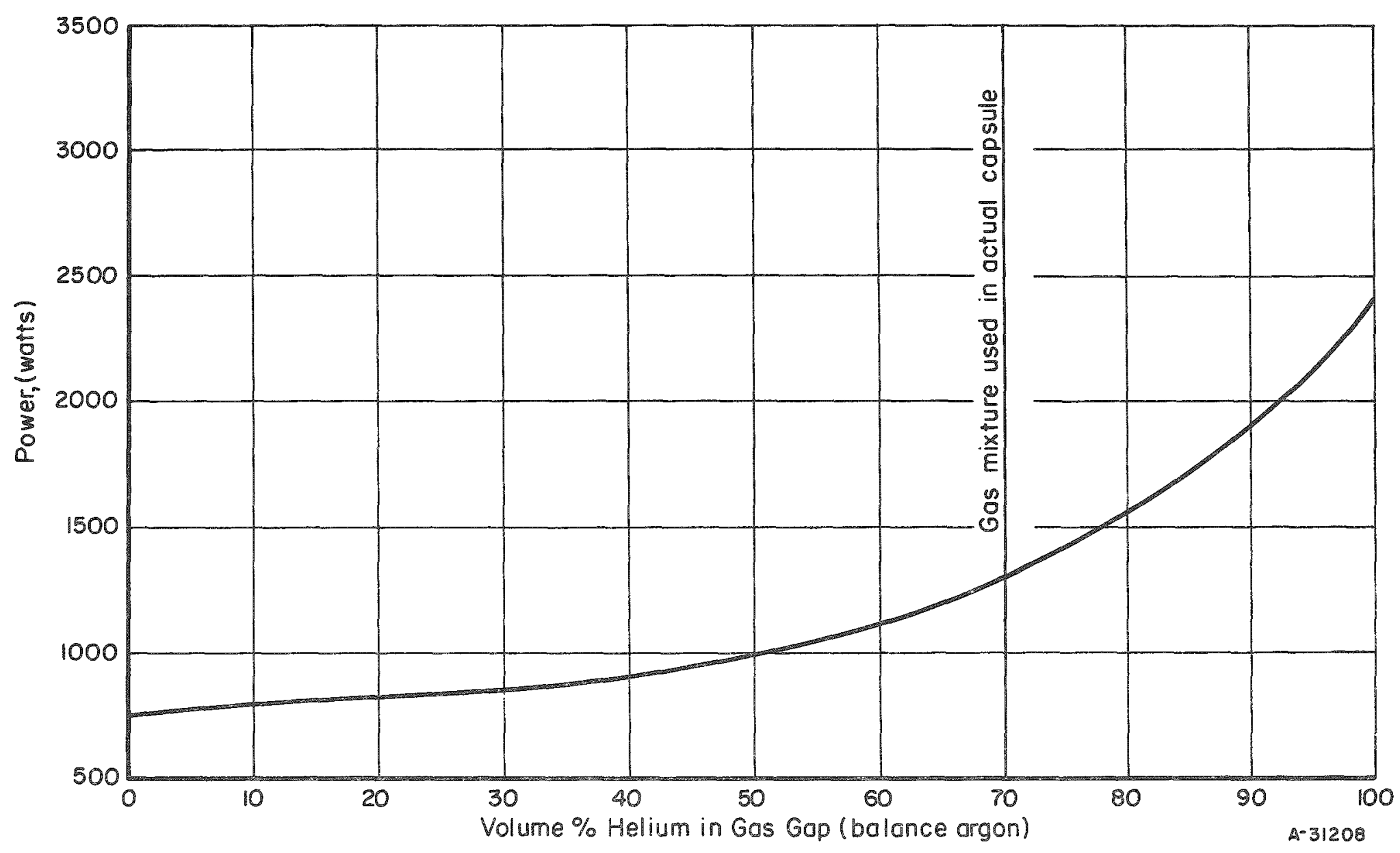

FIGURE 10. ANNULAS GAS COMPOSITION VERSUS POWER REQUIRED TO MAINTAIN THE INNER CRUCIBLE WALL AT $1600^{\circ}$ F IN THE THERMAL MOCKUP CAPSULE 


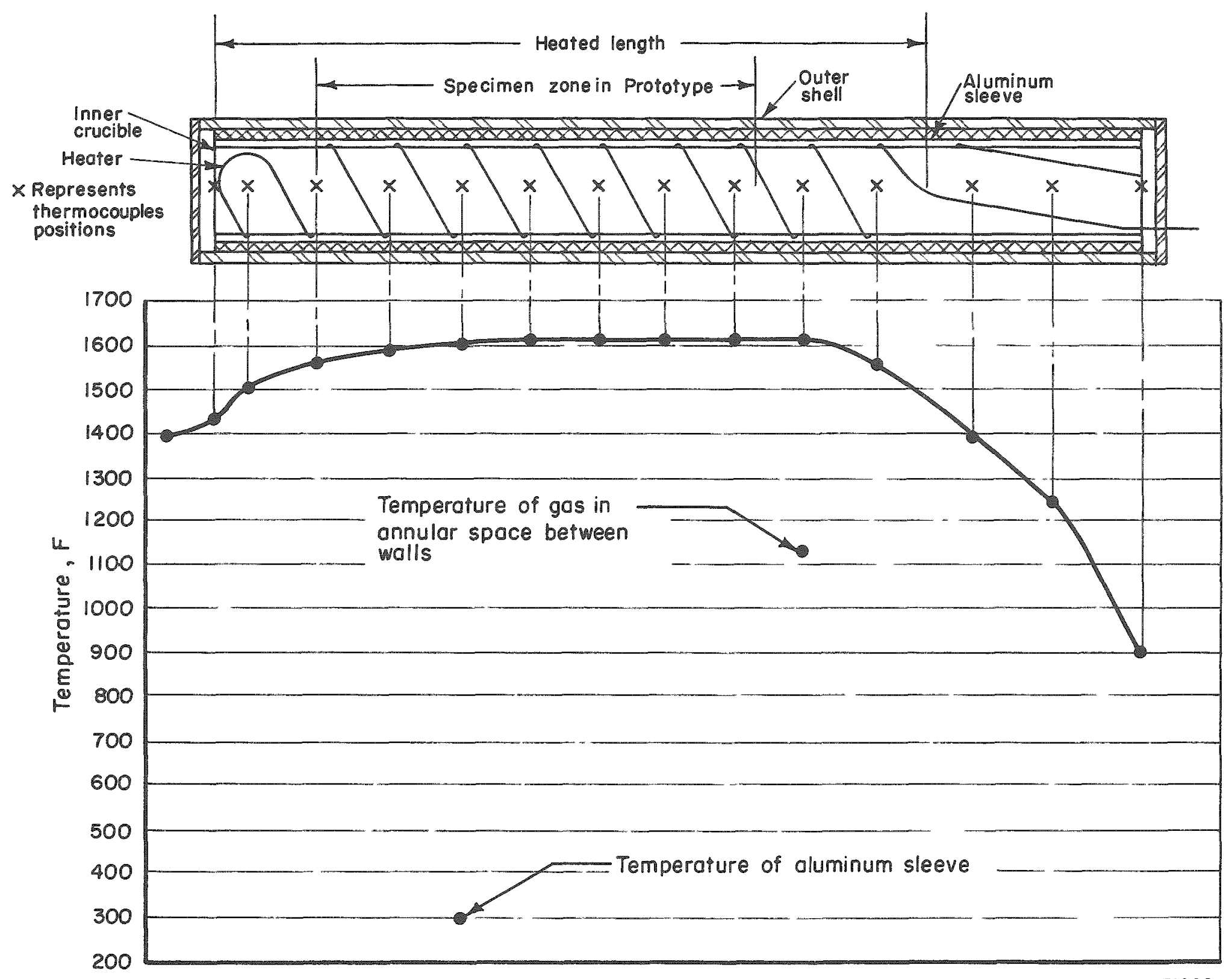

FIGURE 11. SCHEMATIC DIAGRAM OF THERMAL MOCK-UP SHOWING MEASURED TEMPERATURE PROFILE 
Power Requirement $\sim$ watts

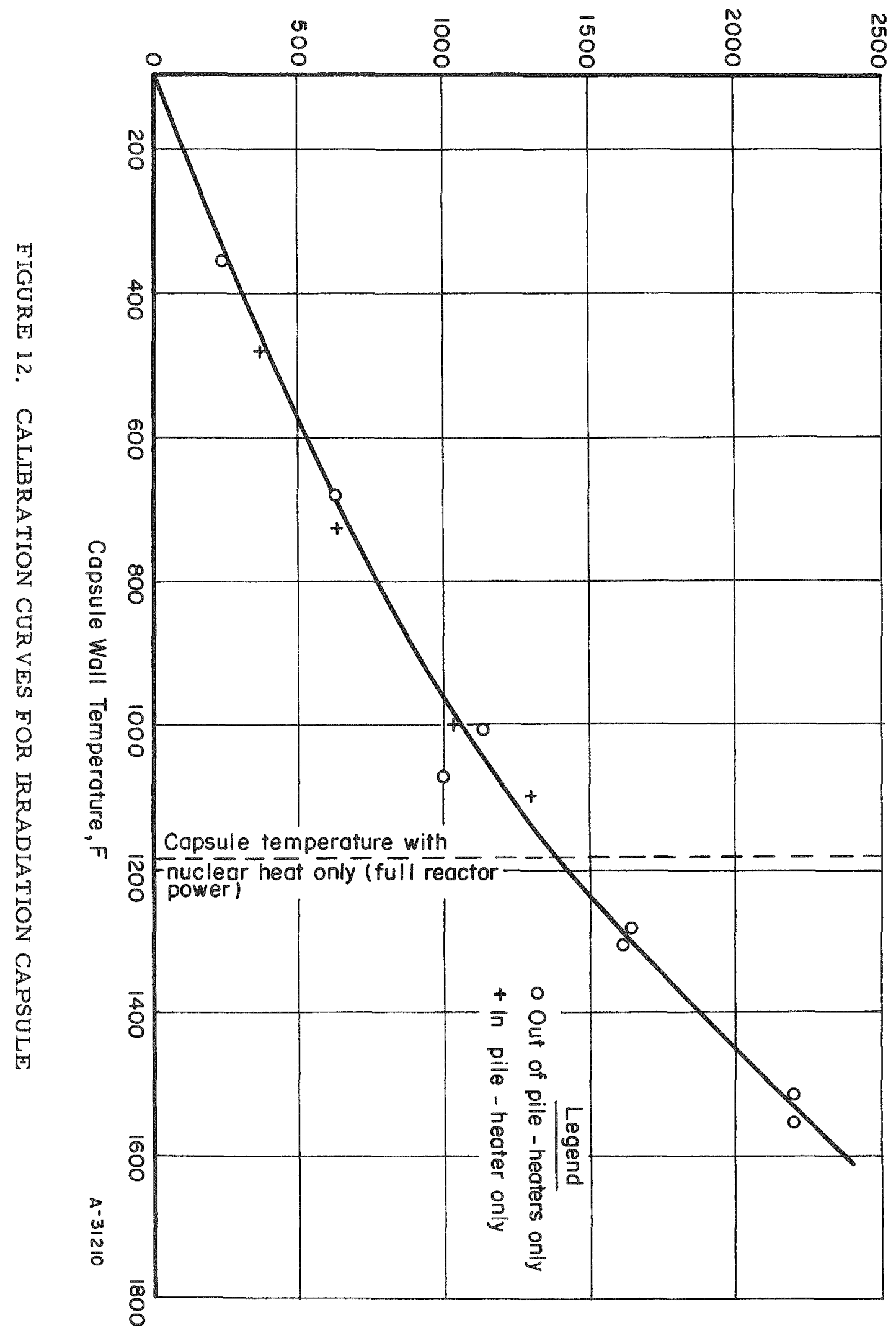


rate of $1200 \mathrm{w}$ and an effective thermal-neutron flux of about $1.5 \times 1013 \mathrm{nv}$. It is emphasized that a flux value arrived at by these methods is probably subject to errors of at least \pm 30 per cent. The careful measurements of an effective flux of $1.1 \times 10^{13} \mathrm{nv}$ by the nuclear-mock-up technique is probably more accurate. At the higher flux, 1 per cent of the contained uranium-235 would be fissioned during each 310 hr of fullpower reactor operation.

Miscellaneous Details

Strength Considerations

It appeared that the internal pressure in the inner crucible might be a limiting feature in the design. A stress analysis was therefore carried out. It was assumed that the wall temperature was $1600 \mathrm{~F}$ and that the internal pressure was $100 \mathrm{psig}$. The pressure arises from the increase in temperature of the blanket gas above the NaK, by constriction of the blanket gas because of thermal expansion of the NaK, and by the presence of the vapor pressure of $\mathrm{NaK}$. The blanket gas is loaded at a pressure of 1 atm and is assumed to be heated to $1600 \mathrm{~F}$. The NaK expands about 30 per cent in test, and its vapor pressure is about $1800 \mathrm{~mm}$ of mercury at $1650 \mathrm{~F}$. The compensating pressure of about 40 psi in the annulus owing to thermal compression was not considered in the pressure analysis. The estimated-100 psig internal pressure is therefore conservative.

The wall thickness was designed by applying the maximum-distortion-energy theory of failure. The design stress level employed was $600 \mathrm{psi}$, which will produce 1 per cent deformation in Type 304 stainless steel held at $1600 \mathrm{~F}$ for $10,000 \mathrm{hr}$. The 10,000-hr rupture stress for this material at $1600 \mathrm{~F}$ is about 1900 psi. Figure 13 is a plot of crucible-wall thickness versus internal pressure to produce a maximum stress of $600 \mathrm{psi}$ in a capped 1.066-in. -OD hollow cylinder. For an internal pressure of 100 psig, the wall thickness required is approximately $105 \mathrm{mils}$; the design thickness chosen was 116 mils.

The end closures for the inner crucible were designed on the basis of flat-plate theory assuming fixed edges and a uniform load over the entire surface. In the case of the top closure, stress-concentration factors were used for the openings required for thermocouple leads. The calculated maximum stress in the top was 760 psi. Since the thermal-mock-up experiments demonstrated that its temperature in service would be considerably below $1600 \mathrm{~F}$, perhaps even as low as $1000 \mathrm{~F}$, there was little concern about the mechanical strength.

The top closure was sealed to the inner crucible by a Heliarc weld made in an inert-atmosphere-filled dry box. During irradiation, this weld would be subjected to a lower temperature than the specimens since it would be above the NaK level. 'The bottom closure did not require a welded joint because the crucible was fabricated by boring a blind hole in a length of solid bar stock. The dimensions selected for the bottom gave a calculated maximum stress of 380 psi. This low value provided a safety margin for stress concentrations. 


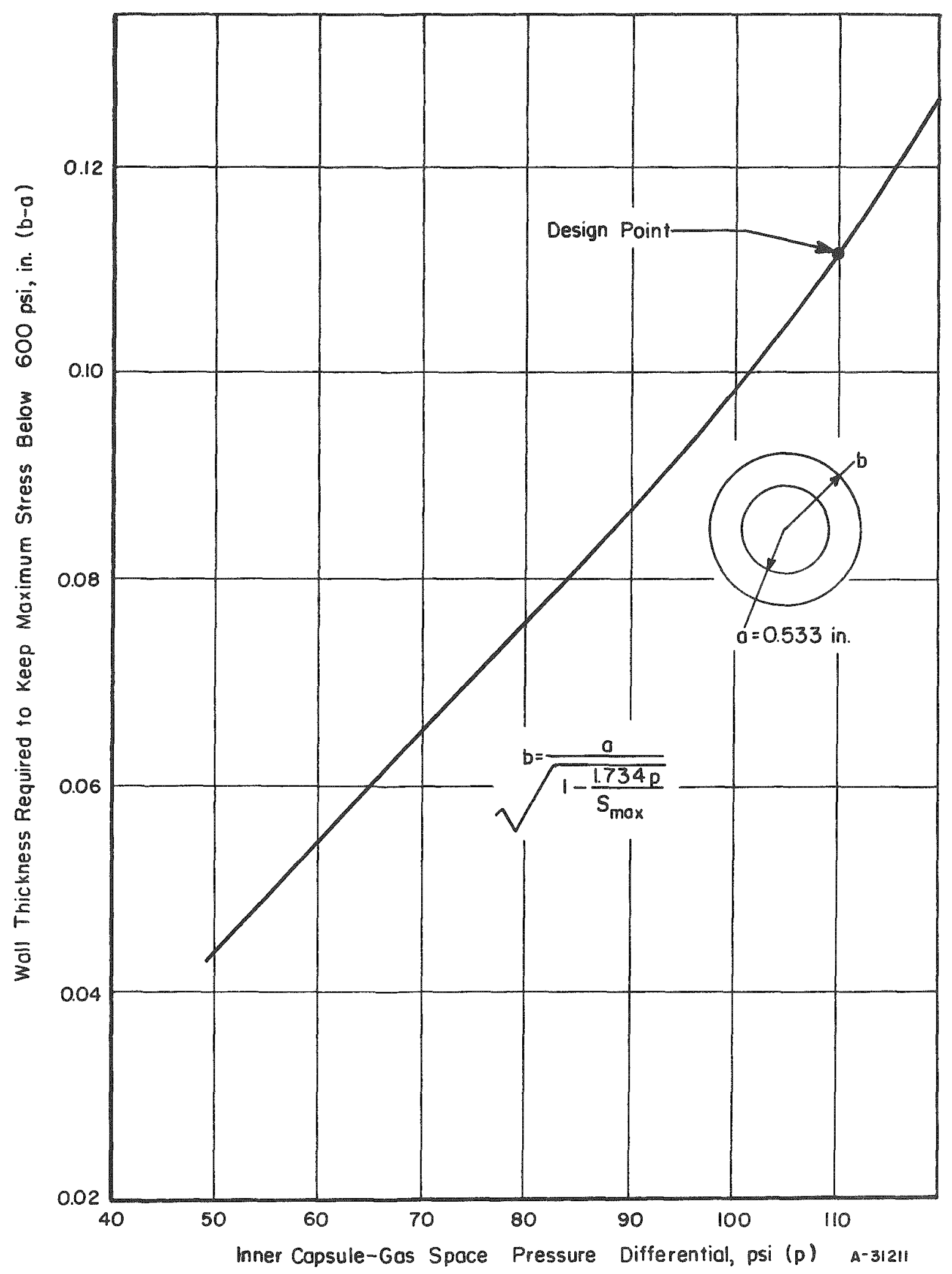

FIGURE 13 CAPSULE WALL THICKNESS REQUIRED FOR STRESSES OE LESS THAN 600 PSI 
Suspensions and Supports

Specimens were suspended by a rod-and-spacer hanger unit with pins through holes in the end sections. Such mounting leaves the specimens free to distort during irradiation.

The inner-crucible support and centering device consisted of four short axial hanger rods at the top, welded to the top closure of the outer shell, and a spider at the bottom. This arrangement maintained concentricity with the outer shell without imposing axial restraint on the inner capsule, thus permitting relative motion owing to differential thermal expansion between the inner and outer shells as a result of heating.

\section{Thermocouples}

Eight NaK-immersed Chromel-Alumel thermocouples were provided. These were 1/16-in. -OD stainless steel-sheathed $\mathrm{MgO}$-insulated units with the sensing ends welded shut by a standard technique employed at Battelle for irradiation-capsule purposes. The couples were located along the axis of the capsule approximately as follows:

(1) One approximately 50 mils from the center of each face of the topmost specimen

(2) One close to the center of one face of each of the remaining specimens

(3) One located about 1 in. below the surface of the NaK, another located near the midpoint of the NaK, and another near the bottom of the crucible.

It is believed that this positioning produced the most reliable temperature-sensing arrangement attainable. Direct attachment to the specimens was not possible.

Seals provided at the thermocouple points of entry into the inner crucible and the outer shell closure were obtained by furnace brazing, using a commercial braze with a remelt temperature slightly higher than $1900 \mathrm{~F}$.

Dosimeter Wires

Two nickel -0.62 w/o cobalt dosimeter wires were provided in the NaK bath along the length of the inner crucible.

\section{Auxiliary Heaters}

As is indicated in Figures 1 and 2, the capsule featured two separate heater coils wrapped around the inner crucible. These were positioned by brazing with a nickelchromium-silicon-iron alloy $\left(\mathrm{GE}_{\mathrm{A}}-81\right)$ applied by furnace brazing; the alloy melting point is about $2300 \mathrm{~F}$. 
The heaters used were stainless steel-sheathed Kanthal elements, $1 / 8$ in. in diameter and about $67 \mathrm{in}$. long. An MgO matrix was used in the heaters and in the nickel lead wires. The nominal power rating of each heater was $1500 \mathrm{w}$.

The seals into the end closure for the outer shell involved a furnace-brazed cylindrical fitting for each sheath end. The final seal was made by welding the fittings to the body of the closure.

\section{Hot-Cell Gas-Sampling Apparatus}

Gas samples are removed from the capsule after irradiation. A small bellows which encases a sharp-pointed plunger is sealed against a flat end closure of the capsule by means of an O-ring seal in the base of the bellows. After the wall is pierced by the plunger, the gas which collects in the bellows chamber is bled into an external system for analysis.

Although the end closures for the inner crucible in the present capsule were too thick to be pierced with the apparatus available, the side wall of this crucible was not. However, to be able to pierce this wall, it was necessary to provide a flat surface against which the bellows-seal device could seat. A boss, which can be seen in Figure 2, was incorporated into the design to serve this purpose. It was brazed to the crucible wall at the same time the heater brazing step was accomplished.

\section{Configuration of Outer Shell}

It was estimated that the outer shell, which was also fabricated of Type 304 stainless steel, would not operate at a temperature higher than $150 \mathrm{~F}$ during normal operation. The outside diameter was within the limit imposed by the desire to introduce the minimum amount of absorber and to displace the least amount of moderator in the reactor. The wall and end-closure thicknesses were chosen to obtain a structure having a very large factor of safety, based on the maximum stress that would occur in the event of a failure of the inner crucible.

\section{Aluminum Sleeve (Heat-Flow Barrier)}

As mentioned previously, an aluminum sleeve was located within the outer shell for heat-transfer control. This sleeve was machined from a bar of $2 S$ aluminum with the inside surface polished. The differential expansion between the stainless steel shell and the aluminum insert resulted in a snug fit during operation. There was approximately $1 / 16$ in. clearance between the heater sheath, brazed to the wall of the inner crucible, and the inner surface of the sleeve.

\section{External Locating Fixture}

An aluminum base similar to those used for fuel-element positioning in the grid plate was fastened to the lower end of the outer shell to maintain the capsule in the center of the 3 by 3 -in. fuel-element space. The water flowing past the capsule exited through the grid passage in which the fixture was held. Eight 1/2-in.-diameter holes were located in the fixture to permit unrestricted flow. 
Capsule-to-Pool Surface Lead Tube

The eight thermocouples and four heater leads were attached to extension leads at points immediately above the lid of the outer shell. Glass-insulated wires were used for thermocouple leads and copper-sheathed $\mathrm{MgO}$-insulated copper wires were used for the heater leads. These leads were sealed in a $7 / 8$-in. -OD stainless steel tube. This tube was welded to the outer shell and, at the pool-surface end, $25 \mathrm{ft}$ away, was attached to a sealed chamber. Standard glass-to-metal seals were used in the wall of this cham ber to make the final lead-wire connections. During the reactor exposure, the lead tube was pressurized with 50 psig of helium and constantly monitored to detect leakage of radioactive gases from the interior of the capsule.

To preclude direct neutron and gamma streaming, the upper half of the lead tube was offset slightly. The offset point was located about $13 \mathrm{ft}$ below the pool surface.

Temperature Instrumentation

External instrumentation was provided to maintain the specified specimen-surface temperature $(1625 \mathrm{~F} \pm 25 \mathrm{~F})$, record the various system temperatures sensed by the thermocouples, and actuate the reactor scram circuit in the event of a temperature rise.

As previously indicated, eight $\mathrm{NaK}$-immersed thermocouples were located in the inner crucible. One of the two positioned near the faces of the topmost specimens was chosen to be the sensing element in the circuit which controlled the auxiliary heat input. The principal element in this circuit was a proportioning-controller recorder which is a high-impedance instrument and thus is able to operate satisfactorily with a long and, consequently, high-resistance thermocouple circuit. This instrument is equipped with a thermocouple break and an upper limit switch (set at approximately $1750 \mathrm{~F}$ during the irradiation period). For purposes of safety, the circuits involved were interlocked with both the auxiliary heating circuit and the reactor control system. Thus, if the control couple opened or if gross overheating was imminent, the heaterpower circuit would be interrupted and reactor scram would occur.

Thermocouples other than the one acting as the control couple were connected to a multipoint Brown Electronik recorder. This recorder is also a rapid-response highimpedance instrument. An alarm system was provided in the recorder circuit to signal any thermocouple malfunction which resulted in an abnormal voltage output. The control-couple circuit was also arranged to actuate this alarm in the event of an output lower than normal. A battery-operated alarm was employed to signal a failure of the power circuit supplying the instrumentation system.

\section{Inspection Procedures During Assembly}

The materials, components, and joints were carefully inspected at each step during the assembly of the capsule. The bar of Type 304 stainless steel from which the inner crucible was fabricated was sectioned, macroetched, and examined microscopically for evidence of porosity and other flaws before machining. The inner surface was carefully polished to remove tool marks and scratches. The heaters and thermocouples were also carefully examined. After welding the sensing ends shut, the thermocouples were checked for flaws by sheath leak checks, radiographs of the end closures 
and beads, and calibrations in proof tests (to $1200 \mathrm{~F}$ ). The heaters were examined visually for surface imperfections and were radiographed to inspect the nickel-Kanthal butt welds. Resistance checks were made after each fabrication step involving the heaters.

All joints were checked for tightness by a mass-spectrometer-type leak detector; where possible, inspections were made by radiography. The leak checks were made with the detector capable of detecting a leak rate of approximately $5 \times 10^{-7} \mathrm{~cm}^{3}$ per sec at STP.

\section{REFERENCES}

(1) Stang, J.H., Goldthwaite, W.H., and Dunnington, B.W., "Design Features of Capsules for High-Temperature Irradiations", BMI-1292 (September 2, 1958 ).

(2) Brown, A.I., and Marco, S.M., Introduction to Heat Transfer, 2nd Edition, McGraw-Hill Book Co., Inc., New York (1951), p 64.

(3) Hirschfelder, J.O., Curtiss, C.F., and Bird, R.B., Molecular Theory of Gases and Liquids, John Wiley and Sons, Inc., New York (1954), p 576.

(4) Deissler, R.G., and Eian, C.S., "Investigation of Effective Thermal Conductivities of Powders", NACA RME52CO5 (June 24, 1952).

(5) Brown, A.I., and Marco, S.M., ibid., p 28.

\section{SJB:JHS:WHG:BWD:cms}

